\title{
Dissociation of Tolerance and Dependence for Opioid Peripheral Antinociception in Rats
}

\author{
K. O. Aley and J. D. Levine \\ Departments of Anatomy, Medicine, and Oral Surgery, and Division of Neuroscience, University of California, San \\ Francisco, California 94143
}

\begin{abstract}
Repeated peripheral administration of the $\mu$-opioid agonist $\left[\mathrm{D}-\mathrm{Ala}{ }^{2}, \mathrm{~N}-\mathrm{Me}-\mathrm{Phe}^{4}, \mathrm{gly}{ }^{5}\right.$-ol] enkephalin (DAMGO) produces acute tolerance and dependence on its peripheral antinociceptive effect against prostaglandin $\mathrm{E}_{2}\left(\mathrm{PGE}_{2}\right)$-induced mechanical hyperalgesia. In this study we evaluated the roles of protein kinase $C$ (PKC) and nitric oxide (NO) in the development of this tolerance and dependence. Repeated administration of PKC inhibitors chelerythrine and 1-(5-isoquinolinesulfonyl)-2-methylpiperazine dihydrochloride with DAMGO did not alter the tolerance to DAMGO; however, dependence (defined as naloxone-induced withdrawal hyperalgesia) was blocked. Repeated administration of $\mathrm{N}$ (n-heptyl)-5-chloro-1-naphthalenesulfonamide, a PKC activator, which alone did not produce tolerance, mimicked the dependence produced by DAMGO. Repeated administration of the NO syn-
\end{abstract}

thase inhibitor $N^{G}$-methyl-L-arginine with DAMGO blocked the development of tolerance to DAMGO but had no effect on the development of dependence. Repeated administration of L-arginine, a NO precursor, mimicked tolerance produced by repeated administration of DAMGO (i.e., the antinociceptive effect of DAMGO was lost); however, L-arginine did not mimic dependence. These findings suggest that the development of acute tolerance and dependence on the peripheral antinociceptive effects of DAMGO have different, dissociable mechanisms. Specifically, PKC is involved in development of $\mu$-opioid dependence, whereas the NO signaling system is involved in the development of $\mu$-opioid tolerance.

Key words: $\mu$-opioids; nitric oxide; pain; protein kinase C; second messenger systems; withdrawal
The repeated or sustained administration of opioids produces tolerance, or loss of effect, and also dependence, manifested by abstinence withdrawal after removal of opioid or precipitated withdrawal after administration of opioid antagonist. Receptor phosphorylation and uncoupling of G-proteins from cell-surface receptors have been implicated in opioid tolerance and dependence (Fukagawa et al., 1992; Escriba et al., 1994; Sim et al., 1996). G-proteins can be coupled from opioid receptors by increased activity of the second messenger protein kinase $\mathrm{C}$ (PKC) (Fukushiama et al., 1994; Lin et al., 1994), and translocation and activation of PKC in spinal cord dorsal horn neurons have been implicated in the development of tolerance and dependence on the antinociceptive effects of morphine (Mayer et al., 1995a,b). The second messenger nitric oxide (NO) has also been suggested to be involved in morphine tolerance (Kolesnikov et al., 1993; Elliott et al., 1995; Herman et al., 1995; Pasternak et al., 1995; Vaupel et al., 1995; Dunbar and Yaksh, 1996); it was demonstrated that the NO synthase (NOS) inhibitor $\mathrm{N}^{\mathrm{G}}$-methyl-Larginine (NMLA) prevents the development of antinociceptive tolerance and/or dependence on systemic morphine in the mouse (Kolesnikov et al., 1993; Majeed et al., 1994).

In addition to their actions in CNS to produce analgesia and other effects, opioids also act in the periphery to block inflammatory mediator-induced hyperalgesia (Levine and Taiwo, 1989; Stein, 1991, 1995; Khasar et al., 1995) and also inhibit primary afferent sensitization in vitro (Gold and Levine, 1996). It has been

Received Jan. 13, 1997; revised Feb. 20, 1997; accepted Feb. 27, 1997.

This work was funded by National Institutes of Health Grant DE08973.

Correspondence should be addressed to Dr. Jon D. Levine, Departments of Anatomy, Medicine, and Oral Surgery, and Division of Neuroscience, Box 0452, University of California, San Francisco, CA 94143-0452.

Copyright (C) 1997 Society for Neuroscience $0270-6474 / 97 / 173907-06 \$ 05.00 / 0$ shown recently that repeated administration of the $\mu$-opioid agonist $\left[\mathrm{D}-\mathrm{Ala}^{2}, N-\mathrm{Me}-\mathrm{Phe}^{4}, \mathrm{gly}{ }^{5}-\mathrm{ol}\right]$ enkephalin (DAMGO) results in tolerance for its ability to produce peripheral antinociception, i.e., to inhibit prostaglandin $\mathrm{E}_{2}\left(\mathrm{PGE}_{2}\right)$-opioid hyperalgesia. Opioid dependence manifested by withdrawal hyperalgesia precipitated by naloxone (Aley et al., 1995) is also produced. In the present study, we evaluated the roles of PKC and NO as second messengers for the development of tolerance and dependence on the peripheral antinociceptive action of the $\mu$-opioid DAMGO to inhibit $\mathrm{PGE}_{2}$-induced hyperalgesia.

\section{MATERIALS AND METHODS}

Animals. Experiments were performed on male Sprague Dawley rats (220-300 gm; Bantin and Kingman, Fremont, CA). Animals were housed in pairs under a $12 \mathrm{hr}$ light/dark cycle, lights on at 6 A.M. Food and water were available ad libitum. All experiments were performed between 10 A.M. and 4 P.M. Experiments were performed under approval of the Institutional Animal Care Committee of the University of California, San Francisco.

Behavioral testing. The nociceptive flexion reflex was quantified with a Basile Analgesymeter (Stoelting, Chicago, IL), which applies a linearly increasing mechanical force to the dorsum of the rat's hindpaw. Before the experiments, rats were exposed to the procedure for $3 \mathrm{~d}$ ( $1 \mathrm{hr}$ daily at 5 min intervals). On the day of the experiment, rats were exposed to the same procedure, and the mean of the last six readings was defined as the baseline threshold (Taiwo et al., 1989; Aley et al., 1995). The mean baseline threshold for the rats used in these experiments was $110.4 \pm 0.4$ (SEM) gm $(n=394)$. Mechanical threshold was redetermined at three time points $(15,20$, and $25 \mathrm{~min})$ after treatments. The mean of these three readings was used to calculate the drug-induced change from the baseline threshold.

Drugs used in this study were $\mathrm{PGE}_{2}$ (a direct-acting hyperalgesic inflammatory mediator) (Pitchford and Levine, 1991; Gold and Levine, 1996), L-arginine hydrochloride (NO precursor), NMLA (NOS inhibitor), and dimethyl sulfoxide (DMSO) (all from Sigma, St. Louis, MO); DAMGO ( $\mu$-opioid receptor agonist), naloxone methyliodide ( $\mathrm{Nal}$; a quaternary salt of naloxone, an opioid receptor antagonist), 1-(5- 


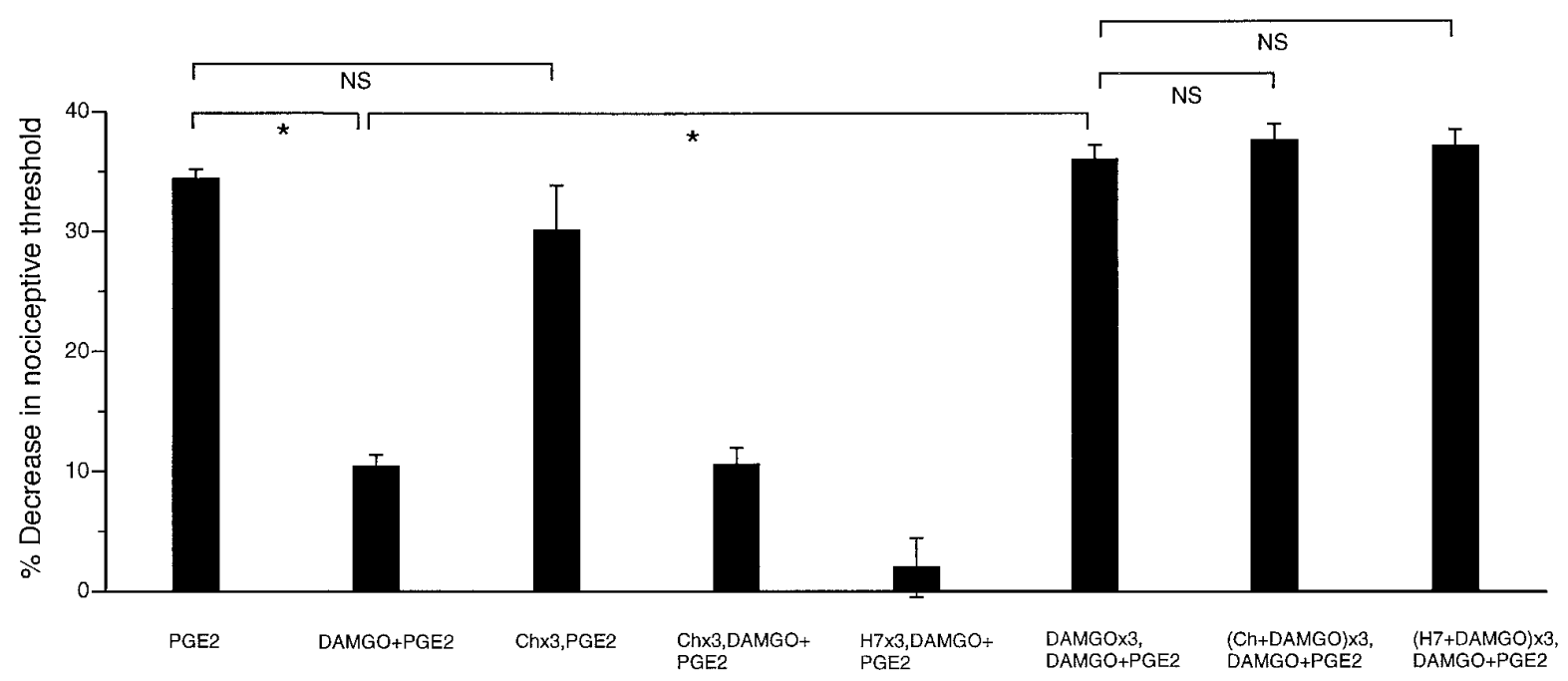

Figure 1. Effect of $\mathrm{PGE}_{2}(100 \mathrm{ng}, P G E 2 ; n=24)$, DAMGO $(1 \mu \mathrm{g})$ plus $\mathrm{PGE}_{2}(D A M G O+P G E 2 ; n=24)$, chelerythrine $(1 \mu \mathrm{g})$ hourly $\times 3$ and at the fourth hour $\mathrm{PGE}_{2}(C h x 3, P G E 2 ; n=12)$ or DAMGO plus PGE $2(C h \times 3, D A M G O+P G E 2 ; n=12)$, H-7 hourly $\times 3$ and at the fourth hour DAMGO plus $\mathrm{PGE}_{2}(H 7 \times 3, D A M G O+P G E 2 ; n=12), \mathrm{DAMGO}$ hourly $\times 3$ and at the fourth hour DAMGO plus PGE $2(D A M G O \times 3, D A M G O+P G E 2 ; n=18)$, chelerythrine plus DAMGO hourly $\times 3$ and at the fourth hour DAMGO plus $\mathrm{PGE}_{2}[(C h+D A M G O) \times 3, D A M G O+P G E 2 ; n=12], \mathrm{H}-7$ plus DAMGO hourly $\times 3$ and at the fourth hour DAMGO plus $\mathrm{PGE}_{2}[(H 7+D A M G O) \times 3, D A M G O+P G E 2 ; n=12]$ on mechanical paw-withdrawal threshold. In this and subsequent figures, ${ }^{*} p<0.05 ; N S$, not statistically significant.

isoquinolinesulfonyl)-2-methylpiperazine dihydrochloride, (H-7; PKC inhibitor), $N$-(n-heptyl)-5-chloro-1-naphthalenesulfonamide (SC-10; PKC activator) (all from RBI, Natick, MA); and chelerythrine chloride (PKC inhibitor) (L. C. Laboratories, Woburn, MA). The selection of the drug doses used in this study was based on the dose-response curves determined during this study or on previous work performed in this laboratory (Aley et al., 1995). A stock solution of $\mathrm{PGE}_{2}(10 \mu \mathrm{g} / 2.5 \mu \mathrm{l})$ was prepared in $100 \%$ ethanol, and further dilutions were made in saline, to a final concentration of ethanol $\leq 1 \%$. DAMGO was dissolved in saline, chelerythrine and $\mathrm{H}-7$ were dissolved in deionized water, and SC-10 was dissolved in DMSO. All drugs administered intradermally were in a volume of $2.5 \mu \mathrm{l}$. When drug combinations were used, they were administered from the same syringe in such a way that the drug mentioned first reached the intradermal site first. The two drugs were separated in the syringe by a small air bubble, to prevent drugs mixing in the syringe.

Statistical analysis. Data are presented as mean \pm SEM of six or more observations in each experimental group. Statistical significance was determined by ANOVA followed by Scheffe's post hoc test, if ANOVA showed a significant difference. $p<0.05$ was considered statistically significant.

\section{RESULTS}

\section{Development of tolerance to DAMGO does not depend on PKC signaling}

Intradermal injection of $\mathrm{PGE}_{2}(100 \mathrm{ng})$ into the hairy skin of the hindpaw of the rat significantly decreased paw-withdrawal threshold ( $p<0.05$ (Fig. 1). DAMGO (1 $\mu \mathrm{g})$ attenuated $\mathrm{PGE}_{2}$ hyperalgesia $(p<0.05)$. Three repeated injections of DAMGO given at intervals of $1 \mathrm{hr}$, when tested $1 \mathrm{hr}$ later, produced tolerance measured as a decrease of antinociception by DAMGO on $\mathrm{PGE}_{2}$ induced hyperalgesia $(p<0.05)$.

Three injections of the PKC inhibitor chelerythrine $(1 \mu \mathrm{g})$, given at intervals of $1 \mathrm{hr}$, did not significantly affect $\mathrm{PGE}_{2}$-induced hyperalgesia $(p>0.05)$ or the antinociceptive effect of DAMGO on $\mathrm{PGE}_{2}$-hyperalgesia $(p>0.05)$. Similarly, three injections of $\mathrm{H}-7(1 \mu \mathrm{g})$, at intervals of $1 \mathrm{hr}$ each, did not attenuate the antinociceptive effect of DAMGO on $\mathrm{PGE}_{2}$-hyperalgesia $(p>$ 0.05). Three injections of chelerythrine or H-7 plus DAMGO, at intervals of $1 \mathrm{hr}$ each, did not affect DAMGO-induced tolerance (both $p>0.05$ ); i.e., neither DAMGO antinociception nor devel- opment of tolerance to DAMGO antinociception was affected by PKC inhibitors.

\section{The development of dependence on DAMGO requires PKC signaling}

The opioid antagonist naloxone methyliodide (at $200 \mathrm{ng}$, the $\mathrm{ID}_{80}$ to inhibit the antinociceptive effect of DAMGO against $\mathrm{PGE}_{2}$ induced hyperalgesia) (Aley et al., 1995), given alone in DAMGO-tolerant paws (i.e., $1 \mathrm{hr}$ after three hourly injections of DAMGO), produced hyperalgesia when compared with vehicletreated paws $(p<0.05)$ (Fig. 2$)$. Chelerythrine $(1 \mu \mathrm{g})$ or H-7 (1 $\mu \mathrm{g})$ coinjected with the three hourly DAMGO injections blocked the development of this naloxone-induced hyperalgesia (both $p<$ $0.05)$; i.e., the development of DAMGO dependence was prevented by $\mathrm{PKC}$ inhibitors.

\section{Activation of PKC in the absence of DAMGO produces a state similar to opioid dependence but not tolerance}

Three injections of SC-10 (PKC activator, $1 \mu \mathrm{g}$ ) alone did not induce significant hyperalgesia $(p>0.05)$ (Fig. 3) or affect $\mathrm{PGE}_{2}$ induced hyperalgesia $(p>0.05)$ or the antinociceptive effect of DAMGO on $\mathrm{PGE}_{2}$-induced hyperalgesia $(p>0.05)$; however, after three hourly injections of SC-10, naloxone given as the fourth hourly injection produced hyperalgesia $(p<0.05)$ (Fig. $3 B)$; i.e., a DAMGO dependent-like state was present. The hyperalgesia induced by naloxone after SC-10 administration was not as great as that induced by naloxone after DAMGO $(p<$ $0.05)$. Naloxone administered without previous SC-10 administration did not induce significant hyperalgesia $(p>0.05)$. Therefore, a PKC activator produced a state similar to opioid dependence but without the characteristics of opioid tolerance.

\section{NO signaling is required for the development of acute tolerance to DAMGO}

The NOS inhibitor NMLA $(1 \mu \mathrm{g})$ had no effect on pawwithdrawal threshold after single (data not shown) or repeated injection; however, NMLA inhibited $\mathrm{PGE}_{2}$-induced hyperalgesia 


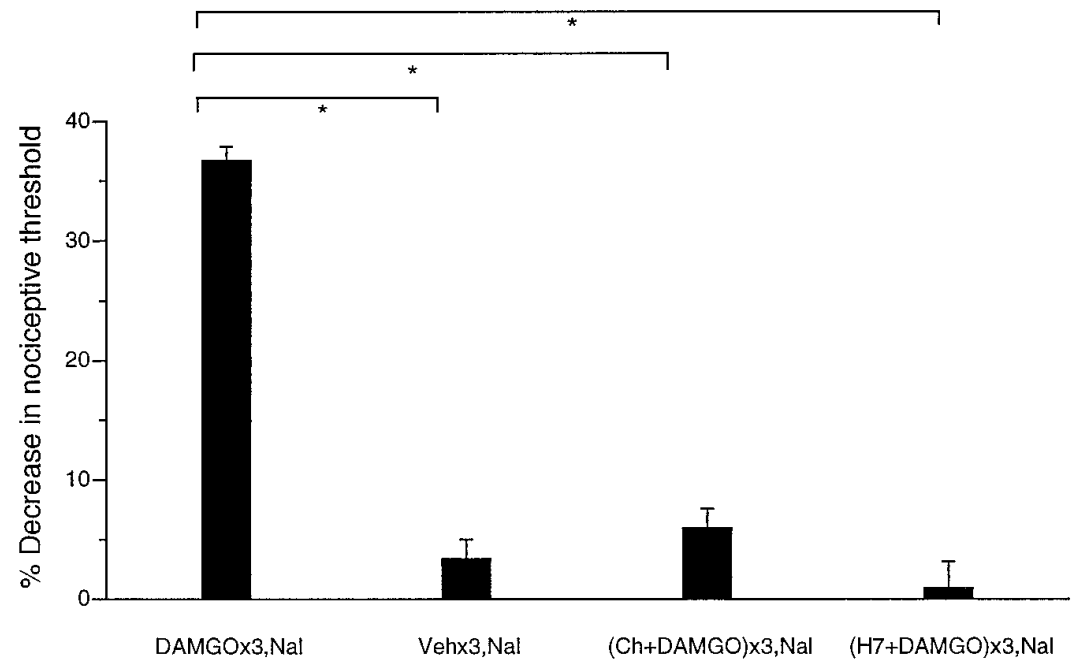

Figure 2. Effect of DAMGO hourly $\times 3$ and at the fourth hour naloxone $(D A M G O \times 3, N a l ; n=16)$, vehicle (saline) hourly $\times 3$ and at the fourth hour naloxone methyliodide $($ Veh $\times 3, \mathrm{Nal} ; n=6)$, chelerythrine plus DAMGO hourly $\times$ 3 and at the fourth hour naloxone methyliodide $[(C h+D A M G O) \times 3, N a l ; n=12], \quad H-7$ plus DAMGO hourly $\times 3$ and at the fourth hour naloxone methyliodide $[(H 7+D A M G O) \times 3, N a l ; n=12]$ on mechanical pawwithdrawal threshold. $(p<0.05)$ (Fig. 4). Therefore, it was not possible to evaluate for an effect of NMLA on tolerance using the previous protocol, because the tolerance assay, $\mathrm{PGE}_{2}$ hyperalgesia, was affected independently; however, $\mathrm{PGE}_{2}$ hyperalgesia had recovered almost completely $72 \mathrm{hr}$ after the previous three injections of NMLA (1 $\mu \mathrm{g})$. Therefore, we assessed for persisting tolerance to DAMGO at $72 \mathrm{hr}$ after three hourly injections of DAMGO and found it present $(p<0.05)$; i.e., there was no effect of DAMGO on $\mathrm{PGE}_{2}$ hyperalgesia. Therefore, an effect of NMLA on tolerance could be evaluated at the $72 \mathrm{hr}$ time point. When three hourly injections of NMLA plus DAMGO were followed by DAMGO plus PGE $_{2} 72$ hr later, DAMGO produced an antinociceptive effect $(p<0.05)$,
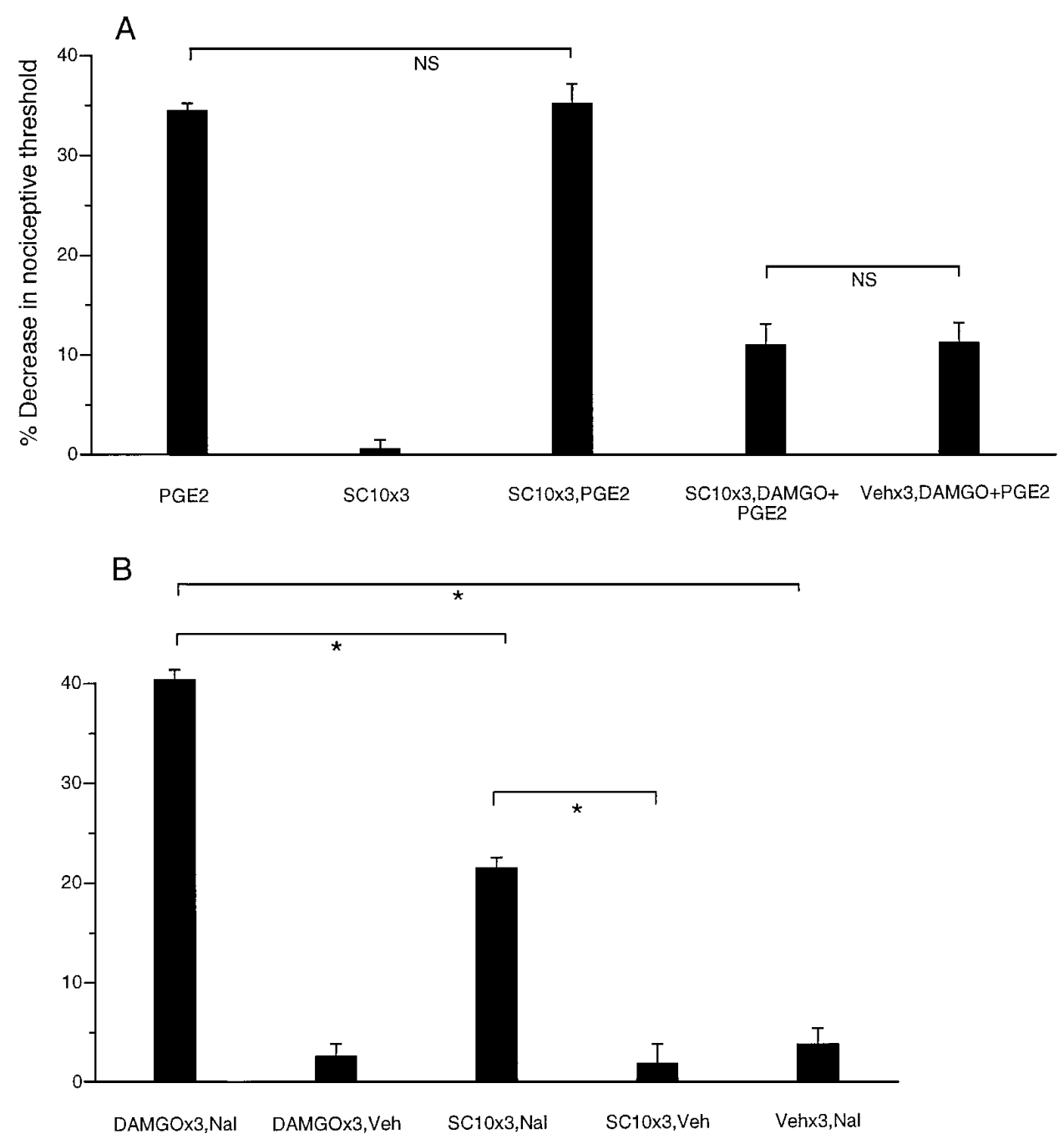

Figure 3. $A$, Effect of SC-10 hourly $\times 3$ $(S C 10 \times 3 ; n=16)$, SC-10 hourly $\times 3$ and at the fourth hour $\mathrm{PGE}_{2}(S C 10 \times 3, P G E 2$; $n=6)$ or DAMGO plus $\mathrm{PGE}_{2}$ $(S C 10 \times 3, D A M G O+P G E 2 ; n=10)$, saline hourly $\times 3$ and at the fourth hour DAMGO plus $\mathrm{PGE}_{2}(\mathrm{Veh} \times 3, D A M G O+P G E 2 ; n=8)$ on mechanical paw-withdrawal threshold. $B$, Effect of DAMGO hourly $\times 3$ and at the fourth hour naloxone methyliodide $(D A M G O \times 3, N a l ; \quad n=16)$, DAMGO hourly $\times 3$ and at the fourth hour vehicle $(D A M G O \times 3, V e h ; n=6)$, SC-10 hourly $\times 3$ and at the fourth hour naloxone methyliodide $(\mathrm{SC10} \times 3, \mathrm{Nal} ; n=16), \quad \mathrm{SC}-10$ hourly $\times 3$ and at the fourth hour vehicle $(S C 10 \times 3, V e h ; n=8)$, vehicle hourly $\times 3$ and at the fourth hour naloxone methyliodide $(\mathrm{Veh} \times 3, \mathrm{Nal} ; n=6)$ on mechanical pawwithdrawal threshold. 


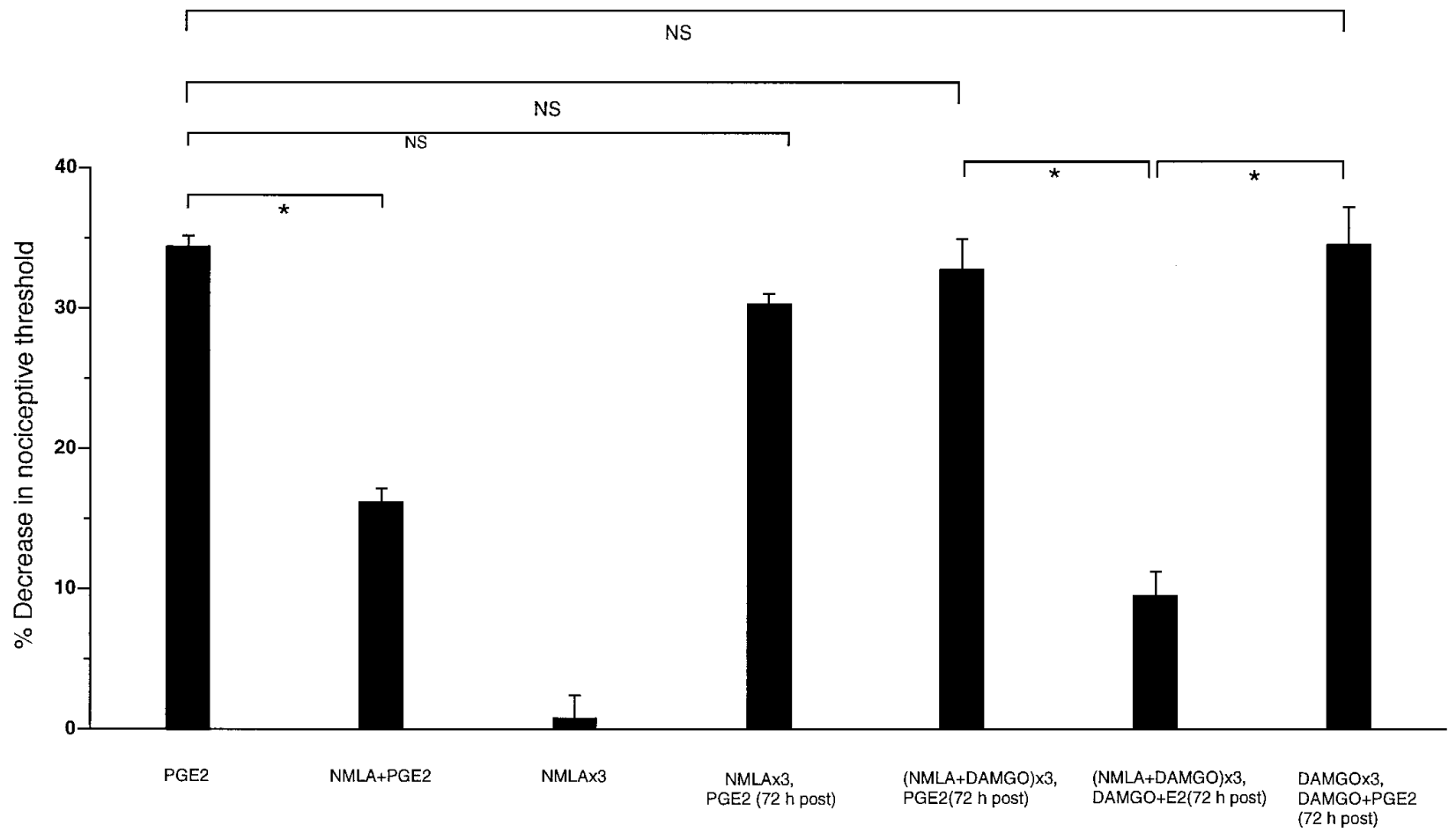

Figure 4. Effect of $\mathrm{PGE}_{2}(\mathrm{PGE} 2)$, NMLA plus PGE 2 (NMLA+PGE2; $\left.\mathrm{n}=10\right)$, NMLA hourly $\times 3(\mathrm{NMLA} \times 3 ; \mathrm{n}=6)$, NMLA hourly $\times 3$ and 72 hour post-PGE $2[N M L A \times 3, P G E 2(72 h$ post $) ; n=12]$, NMLA plus DAMGO hourly $\times 3$ and $\mathrm{PGE}_{2} 72$ hour later $[(N M L A+D A M G O) \times 3, P G E 2(72 h$ post $)$; $n=12]$, NMLA plus DAMGO hourly $\times 3$ and $72 \mathrm{hr}$ post DAMGO plus PGE 2 [(NMLA+DAMGO) $\times 3, D A M G O+P G E 2(72 h$ post $) ; n=12]$, and DAMGO hourly $\times 3$ and DAMGO plus PGE $_{2} 72$ hr post $[D A M G O \times 3, D A M G O+P G E 2(72 h$ post $) ; n=8]$ on mechanical paw-withdrawal threshold.

indicating that administration of the NOS inhibitor NMLA with DAMGO prevented the development of tolerance. As a control, the effect of NMLA plus DAMGO for three hourly injections, on $\mathrm{PGE}_{2}$ hyperalgesia at $72 \mathrm{hr}$, was tested; $\mathrm{PGE}_{2}$ hyperalgesia was not affected $(p>0.05)$.

\section{NO signaling is not required for development of dependence on DAMGO}

Administration of naloxone $1 \mathrm{hr}$ after three hourly injections of NMLA plus DAMGO resulted in significant hyperalgesia $(p<$ 0.05 ) (Fig. 5), similar to the withdrawal hyperalgesia produced by naloxone after DAMGO alone; administration of vehicle after three similar injections had no effect. Therefore, inhibition of NOS does not affect the development of DAMGO-induced dependence.

\section{Activation of NO system produces a state similar to opioid tolerance but not dependence}

Intradermal injection of the NO precursor L-arginine (100 ng) alone produced hyperalgesia $(p<0.05)$ (Fig. 6A), which increased with three hourly injections $(p<0.05)$. At $72 \mathrm{hr}$ after the last injection, however, paw-withdrawal threshold had returned to
Figure 5. Effect of DAMGO hourly $\times 3$ and at the fourth hour naloxone methyliodide $(D A M G O \times 3, \mathrm{Nal} ; n=16)$, vehicle (saline) hourly $\times 3$ and at the fourth hour naloxone methyl iodide $(\mathrm{Veh} \times 3, \mathrm{Nal} ; n=6)$, NMLA plus DAMGO $\times 3$ and at the fourth hour naloxone $[(N M L A+D A M G O) \times 3, \quad N a l ; n=10], \quad$ NMLA plus DAMGO hourly $\times 3$ and at the fourth hour saline $[(N M L A+D A M G O) \times 3, V e h ; n=6]$ on mechanical pawwithdrawal threshold.

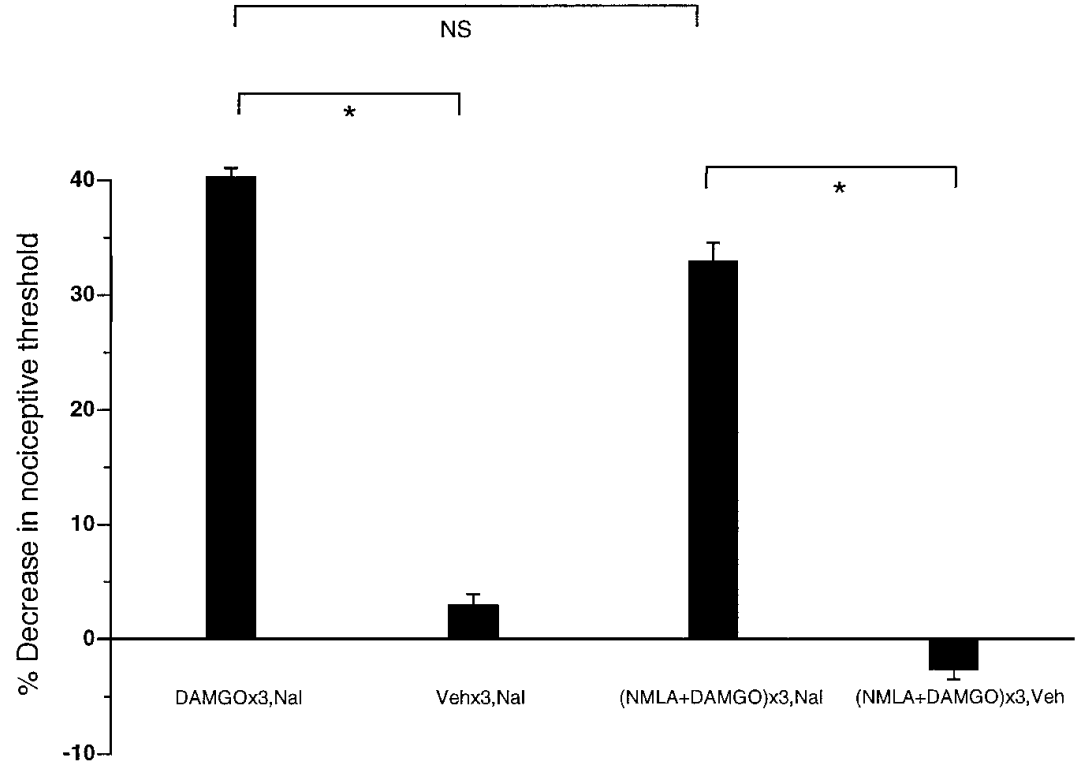


A

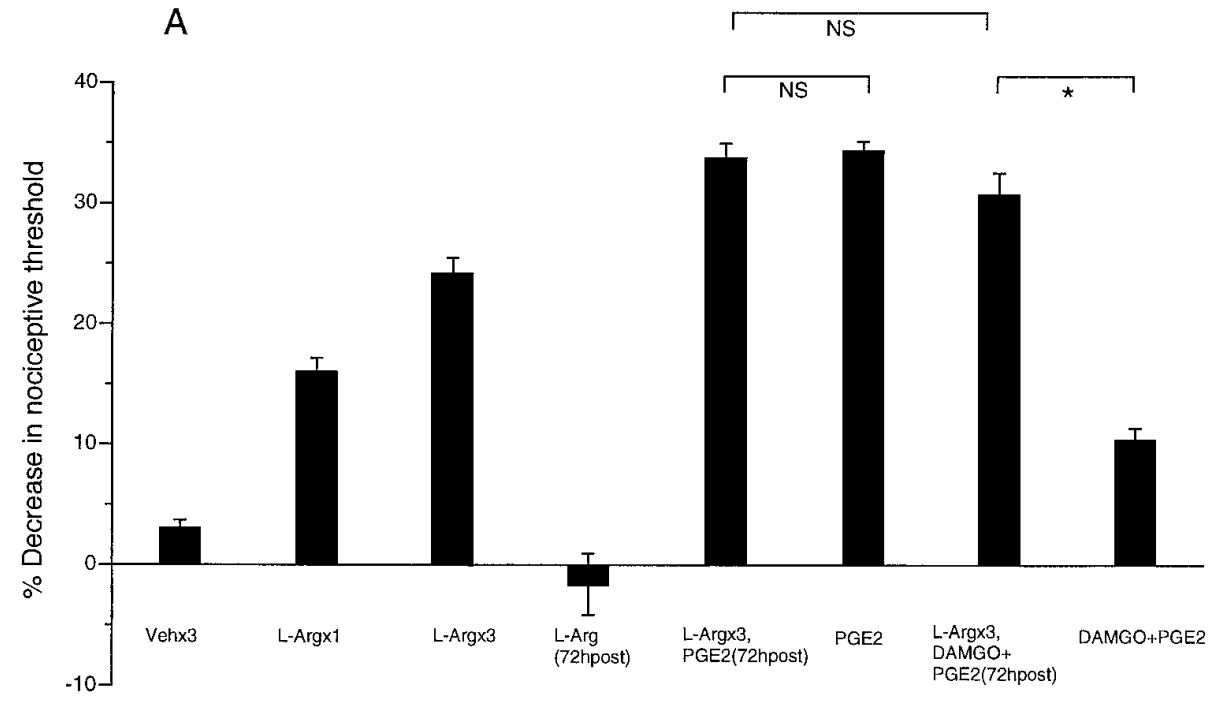

B

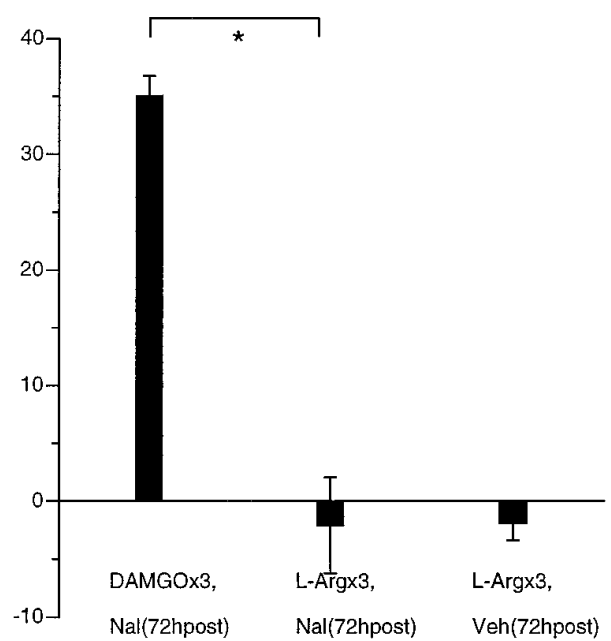

Figure 6. A, Effect of three hourly injections of vehicle (saline) $(\operatorname{Veh} \times 3 ; n=6)$, L-arginine $(100 \mathrm{ng})(L-\operatorname{Arg} \times 1 ; n=12)$, three hourly injections of L-arginine $(L-A r g \times 3 ; n=12), 72 \mathrm{hr}$ after three hourly injections of L-arginine [L-Arg $\times 3(72 h p o s t) ; n=12]$, PGE 272 hr after three hourly injections of L-arginine $[L-A r g \times 3, P G E 2(72 h p o s t) ; n=6], P_{2} E_{2}$ (PGE2), DAMGO plus PGE $_{2} 72 \mathrm{hr}$ after three hourly injections of L-arginine $[L-A r g \times 3, D A M G O+P G E 2(72 h p o s t) ; n=12]$, DAMGO plus $\mathrm{PGE}_{2}(D A M G O+P G E 2)$, on mechanical paw-withdrawal threshold. $B$, Effect of three hourly injections of DAMGO and $72 \mathrm{hr}$ after naloxone methyliodide [DAMGO $\times 3, \mathrm{Nal}(72 \mathrm{hpost})]$, naloxone methyl iodide $72 \mathrm{hr}$ after three hourly injections of L-arginine [L-Arg $\times 3, \operatorname{Nal}(72 h$ post $) ; n=8]$, vehicle $72 \mathrm{hr}$ after three hourly injections of L-arginine $[L-A r g \times 3, \operatorname{Veh}(72 h p o s t) ; n=8]$, on mechanical paw-withdrawal threshold.

the basal level, and the magnitude of hyperalgesia produced by $\mathrm{PGE}_{2}$ was similar to that in normal animals $(p>0.05)$. Therefore, an effect of L-arginine to produce a tolerant-like or dependentlike state was assessed $72 \mathrm{hr}$ after the last injection of L-arginine; DAMGO inhibition of $\mathrm{PGE}_{2}$-induced hyperalgesia was reduced $(p<0.05)$; i.e., the antinociceptive effect of DAMGO was similar to that in DAMGO-tolerant animals (Fig. 1). After similar treatment, however, the opioid antagonist naloxone methyliodide did not produce hyperalgesia (Fig. $6 B$ ), in contrast to the significant hyperalgesia produced by naloxone in tolerized animals (Fig. 2). Injection of vehicle $72 \mathrm{hr}$ after the last of three hourly injections of L-arginine did not significantly affect mechanical nociceptive threshold $(p>0.05)$ (Fig. $6 B)$. Therefore, administration of the NO donor L-arginine produced an opioid tolerant-like but not dependent-like state.

\section{DISCUSSION}

Our data strongly suggest that the development of $\mu$-opioid acute tolerance for peripheral antinociception involves NO but not PKC signaling mechanisms, and that the development of dependence involves PKC but not NO signaling mechanisms. These findings support the hypothesis that there are different mechanisms for the development of tolerance and dependence on the peripheral antinociceptive effect of the $\mu$-opioid agonist DAMGO.

The hyperalgesia produced by naloxone after repeated administration of the PKC activator SC-10 was significant but less than that produced by naloxone after similar treatment with the $\mu$-opioid DAMGO. A tenfold increase in the dose of SC-10 produced no further increase in the naloxone-induced hyperalgesia (unpublished observation), suggesting that other mechanisms in addition to PKC contribute to the development of dependence. Because PKC antagonists completely block the development of dependence, however, our results suggest that PKC activity is necessary for dependence to develop. Of note, what we report as dependence refers to naloxone-precipitated withdrawal hyperal- gesia; animals may not have been followed for a long enough period of time to observe a hyperalgesic syndrome after cessation of opioids.

The development of tolerance to an opioid agonist generally is accompanied by the development of dependence. Various clinical and experimental studies suggest that the two phenomena are closely related (Loh et al., 1969; Way et al., 1969; Klee and Nirenberg, 1974; Sharma et al., 1977). Recent evidence, however, has suggested that dependence may occur independently. A temperature-dependent functional dissociation of tolerance and dependence on morphine has been demonstrated in guinea-pig in vitro (David et al., 1993). Our results demonstrate that in the model of peripheral antinociception, tolerance and dependence can be dissociated. Some previous studies, in agreement with our findings, report reduction of opioid-induced tolerance in the CNS by NOS inhibitors (Kolesnikov et al., 1992, 1993; Elliott et al., 1994; Bhargava and Zhao, 1996) and the attenuation in the CNS of antagonist-induced hyperalgesia by PKC inhibitors (Tokuyama et al., 1995a,b). In contrast, studies of opioid tolerance in the CNS report prevention of tolerance by PKC inhibitors (Narita et al., 1994, 1995; Bilsky et al., 1996) and prevention of dependence as well as tolerance by NOS inhibitors (Majeed et al., 1994; Bhargava, 1995), different from our findings. These disparities may reflect differences in peripheral and central mechanisms of $\mu$-opioid tolerance and dependence and/or be attributable to the complexity of neuronal interaction in the CNS.

\section{Conclusion}

The results of this study demonstrate, for the first time, in vivo dissociation of opioid acute tolerance and dependence. Pharmacological agents selectively affecting PKC and NO second messenger systems affected either opioid dependence or opioid tolerance, respectively. After administration of these agents, individual animals could demonstrate a tolerance-like but not dependence-like state and vice versa. The results have potential 
significance for the clinical use of opioids as well as for future study of mechanisms that underlie opioid tolerance and dependence.

\section{REFERENCES}

Aley KO, Green PG, Levine JD (1995) Opioid and adenosine peripheral antinociception are subject to tolerance and withdrawal. J Neurosci 15:8031-8038.

Bhargava HN (1995) Attenuation of tolerance to, and physical dependence on, morphine in the rat by inhibition of nitric oxide synthase. Gen Pharmacol 26:1049-1053.

Bhargava HN, Zhao GM (1996) Effect of nitric oxide synthase inhibition on tolerance to the analgesic action of D-Pen2,D-Pen5,enkephalin and morphine in the mouse. Neuropeptides 30:219-223.

Bilsky EJ, Bernstein RN, Wang Z, Sadee W, Porreca (1996) Effects of naloxone and D-Phe-Cys-Tyr-D-Trp-Arg-Thr-Pen-Thr-NH2 and the protein kinase inhibitors $\mathrm{H} 7$ and $\mathrm{H} 8$ on acute morphine dependence and antinociceptive tolerance in mice. $\mathrm{J}$ Pharmacol Exp Ther 277:484-490.

David C, Davis N, Mason R, Wilson VG (1993) Evidence for functional dissociation of dependence and tolerance in guinea-pig isolated ileal segments following $20 \mathrm{hr}$ exposure to morphine in vitro. $\mathrm{Br} \mathrm{J}$ Pharmacol 110:1522-1526.

Dunbar S, Yaksh TL (1996) Effect of spinal infusion of L-NAME, a nitric oxide synthase inhibitor, on spinal tolerance and dependence induced by chronic intrathecal morphine in the rat. Neurosci Lett 207:33-36.

Elliott K, Minami N, Kolesnikov YA, Pasternak GW, Inturrisi CE (1994) The NMDA receptor antagonists, LY274614 and MK-801, and the nitric oxide synthase inhibitor, NG-nitro-L-arginine, attenuate analgesic tolerance to the mu-opioid morphine but not to kappa opioids. Pain 56:69-75.

Elliott K, Kest B, Man A, Kao B, Inturrisi CE (1995) N-methyl-Daspartate (NMDA) receptors, mu and kappa opioid tolerance, and perspectives on new analgesic drug development. Neuropsychopharmacology 13:347-356.

Escriba PV, Sastre M, Garcia SJ (1994) Increased density of guanine nucleotide-binding proteins in the postmortem brains of heroin addicts. Arch Gen Psychiatry 51:494-501.

Fukagawa Y, Funada M, Mizoguchi H, Narita M, Suzuki T, Misawa M (1992) Effects of dietary proteins on analgesic activity of tolerance and physical dependence on morphine in rats. Arukoru Kenkyuto Yakubutsu Izon 27:266-75.

Fukushiama N, Ueda H, Hayashi C, Katayama T, Miyamae T, Misu Y (1994) Species and age differences of functional coupling between opioid $\mu$-receptor and G-proteins and possible involvement of protein kinase $\mathrm{C}$ in striatal membranes. Neurosci Lett 176:55-58.

Gold M, Levine J (1996) DAMGO inhibits prostaglandin $\mathrm{E}_{2}$-induced potentiation of a TTX-resistant $\mathrm{Na}^{+}$current in rat sensory neurons in vitro. Neurosci Lett 212:83-86.

Herman BH, Vocci F, Bridge P (1995) The effects of NMDA receptor antagonists and nitric oxide synthase inhibitors on opioid tolerance and withdrawal: medication development issues for opiate addiction. Neuropsychopharmacology 13:269-293.

Khasar S, Wang F, Taiwo Y, Heller P, Green P, Levine J (1995) Muopioid agonist enhancement of prostaglandin-induced hyperalgesia in rat: a G-protein $\beta \gamma$ subunit-mediated effect? Neuroscience 67:189-195.

Klee WA, Nirenberg M (1974) A neuroblastoma and glioma hybrid cell line with morphine receptors. Proc Natl Acad Sci USA 71:3474-3477.

Kolesnikov YA, Pick CG, Pasternak GW (1992) NG-nitro-L-arginine prevents morphine tolerance. Eur J Pharmacol 221:399-400.
Kolesnikov YA, Pick CG, Ciszewska G, Pasternak GW (1993) Blockade of tolerance to morphine but not to kappa opioids by a nitric oxide synthase inhibitor. Proc Natl Acad Sci USA 90:5162-5166.

Levine JD, Taiwo YO (1989) Involvement of the mu-opiate receptor in peripheral analgesia. Neuroscience 32:571-575.

Lin H, Carter BD, Haas KF, Medzihradsky F (1994) Modulation of opioid signal transduction in SH-SY5Y neural cells by differentiating agents: concurrent mu receptor upregulation and effector desensitization by phorbol ester. Regul Pept 50:S21-S22.

Loh HH, Shen EH, Way EL (1969) Inhibition of morphine tolerance, and physical dependence development and brain serotonin synthesis by cycloheximide. Biochem Pharmacol 18:2711-2721.

Majeed NH, Przewlocka B, Machelska H, Prezewlocki R (1994) Inhibition of nitric oxide synthase attenuates the development of morphine tolerance and dependence in mice. Neuropharmacology 33:189-192.

Mayer DJ, Mao J, Price DD (1995a) The development of morphine tolerance and dependence is associated with translocation of protein kinase C. Pain 61:365-374.

Mayer DJ, Mao J, Price DD (1995b) The association of neuropathic pain, morphine tolerance and dependence, and the translocation of protein kinase C. Nida Res Monogr 147:269-298.

Narita M, Feng Y, Makimura M, Hoskins B, Ho IK (1994) A protein kinase inhibitor $\mathrm{H}-7$, inhibits the development of tolerance to opioid antinociception. Eur J Pharmacol 271:543-545.

Narita M, Narita M, Mizoguchi H, Tseng LF (1995) Inhibition of protein kinase $\mathrm{C}$, but not of protein kinase $\mathrm{A}$, blocks the development of acute antinociceptive tolerance to an intrathecally administered mu-opioid receptor agonist in the mouse. Eur J Pharmacol 280:R1-3.

Pasternak GW, Kolesnikov YA, Babey AM (1995) Perspectives on the $N$-methyl-D-aspartate/nitric oxide cascade and opioid tolerance. Neuropsychopharmacology 13:309-313.

Pitchford S, Levine JD (1991) Prostaglandins sensitize nociceptors in cell culture. Neurosci Lett 132:105-108.

Sharma SK, Klee WA, Nirenberg M (1977) Opiate-dependent modulation of adenylate cyclase. Proc Natl Acad Sci USA 74:3365-3369.

Sim LJ, Selley DE, Dworkin SI, Childers SR (1996) Effects of chronic morphine administration on $\mu$ opioid receptor-stimulated $\left[{ }^{35} \mathrm{~S}\right] \mathrm{GTP} \gamma \mathrm{S}$ autoradiography in rat brain. J Neurosci 16:2684-2692.

Stein C (1991) Peripheral analgesic actions of opioids. J Pain Symptom Manage 6:119-124.

Stein C (1995) The control of pain in peripheral tissue by opioids. N Engl J Med 332:1685-1690.

Taiwo YO, Coderre TJ, Levine JD (1989) The contribution of training to sensitivity in the nociceptive paw-withdrawal test. Brain Res 487:148-151.

Tokuyama S, Feng Y, Wakabayashi H, Ho IK (1995a) $\mathrm{Ca}^{2+}$ channel blocker, diltiazem, prevents physical dependence and enhancement of protein kinase $\mathrm{C}$ activity by opioid infusion in rats. Eur $\mathrm{J}$ Pharmacol 279:93-98.

Tokuyama S, Feng Y, Wakabayashi H, Ho IK (1995b) Possible involvement of protein kinases in physical dependence on opioids: studies using protein kinase inhibitors, H-7 and H-8. Eur J Pharmacol 284:101-107.

Vaupel DB, Kimes AS, London ED (1995) Nitric oxide synthase inhibitors: preclinical studies of potential use for treatment of opioid withdrawal. Neuropsychopharmacology 13:315-322.

Way EL, Loh HH, Shen FH (1969) Simultaneous quantitative assessment of morphine tolerance and physical dependence. J Pharmacol Exp Ther 167:1-8. 